\title{
Research on Transforming 3D Cinema to 3DTV Method
}

\author{
Fang Lu \\ Academy of Fine Arts, Dalian University, Dalian, China, 116622 \\ E-mail:shining_112@live.cn
}

Keywords: 3D cinema; 3DTV;Depth quality;Visual comfort.

\begin{abstract}
D cinema and 3DTV are at two different levels in the screen size spectrum. When the same stereoscopic-3D content is viewed on a cinema screen and 3DTV screen, it will produce a different 3D impression. As a result, it is difficult to fulfill the requirements of 3DTV with content captured for $3 \mathrm{D}$ cinema. Thus, it is important to properly address the issue of 3DTV content creation to avoid possible delays in the deployment of 3DTV. In this paper, we first explore the effects of using the same content for 3D cinema and 3DTV and then analyze the performance of several disparity based transformations for 3D cinema to 3DTV content conversion, by subjective testing. Effectiveness of the transformations is analyzed in terms of both depth quality and visual comfort of 3D experience. We show that by using a simple shift-based disparity transformation technique, it is possible to enhance the 3DTV experience from a common input signal which is originally captured for cinema viewing.
\end{abstract}

\section{Introduction}

3D cinema and 3DTV have grown in popularity in recent years. With the advances in the optical and communication technology [1], 3DTV has now become a reality. Today, auto stereoscopic 3D displays are available to provide binocular depth perception without the hindrance of specialized headgear or filter or shutter glasses. Thus, with the comfort of the sofa in their living room, viewers have now the opportunity to feel a stronger excitement as their favorite football team scores the winning goal or the serenity of a rain forest with the butterflies flying around them.

"3D" perceived from viewing stereoscopic contentdepends on the viewing geometry [2]. 3D cinema and 3DTVcorrespond to different screen sizes and viewing distances. When the same stereoscopic-3D content is viewed on acinema screen and 3DTV screen, it will produce a different3D impression (with regards to apparent depth androundness of objects) [3]. This implies that the 3D contentmust be captured for a specific viewing geometry, i.e., thetargeted screen size and viewing distance, in order toprovide a satisfactory 3D experience. Although it would bepossible, it is clearly not viable to produce and transmitmultiple streams of the same content for different screensizes. Several studies have been carried out to address theissues associated with 3DTV content creation $[4,5,6]$. Inthis paper, we first explore the effects of using the samecontent for 3D cinema and 3DTV and then analyze theperformance of several global-shift based disparitytransformations for 3D cinema to 3DTV content conversionprocess. Effectiveness of these transformations is assessedusing subjective testing of both depth quality and visualcomfort of 3D experience. We show that, by using a simpleshift-based disparity transformation technique, it is possibleto enhance the 3DTV experience from a common inputsignal which is originally captured for cinema viewing [7]. 


\section{From Cinema to 3DTV}

To understand the effect on depth perception under no transformation approach, first let us study the basis geometry of 3D cinema and 3DTV content viewing. The basis geometry of this interpretation and how depth of an object is seen is shown in ray diagram form in figure 1 , for both cinema and 3DTV screens [8].

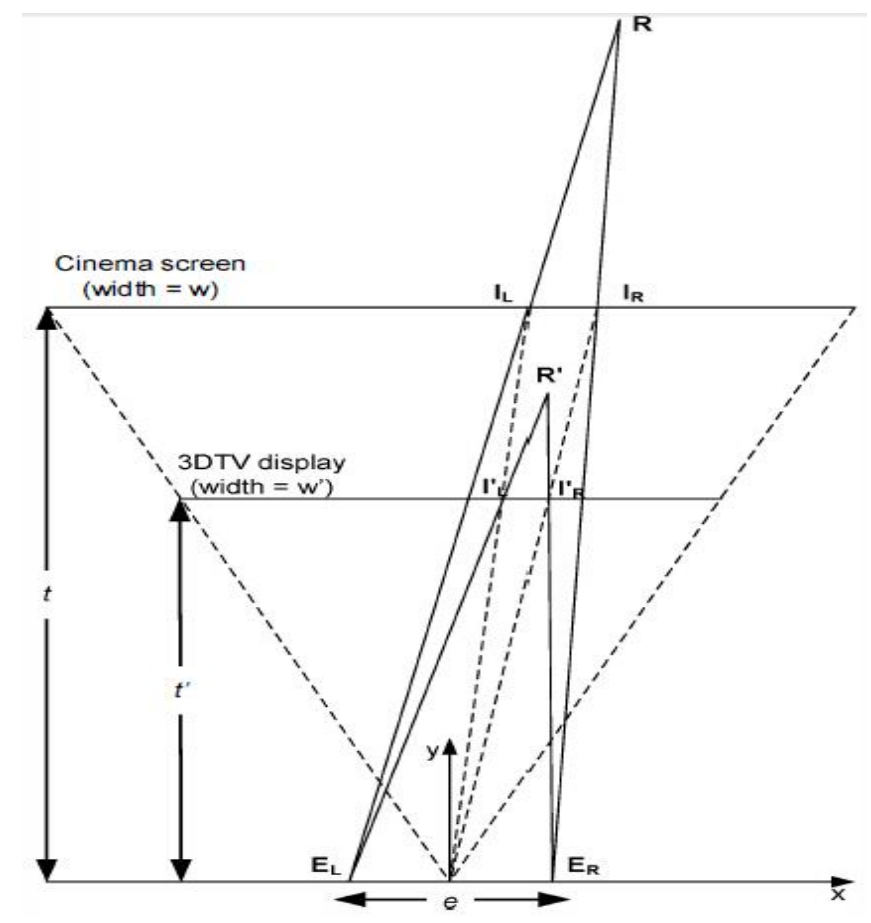

Figure.1 Viewing geometry of 3D cinema and 3DTV

The variables used are described in Table 1. It is assumed that the spectator watches the $3 \mathrm{D}$ video with the same angle. Thus theviewing distance has to change with proportion to the display width [9].

Table1 Variables considered in figure

\begin{tabular}{|c|c|}
\hline Location of the eyes & $\mathrm{E}_{\mathrm{L}}\left(\mathrm{e}_{\mathrm{L}}^{\mathrm{x}}, 0\right), \mathrm{E}_{\mathrm{R}}\left(\mathrm{e}_{\mathrm{R}}^{\mathrm{x}}, 0\right)$ \\
\hline Eye distance & $\mathrm{e}$ \\
\hline Object point & Cinema: $\mathrm{R}\left(\mathrm{R}_{\mathrm{X}}, \mathrm{R}_{\mathrm{Y}}\right) / 3 \mathrm{DTV}: \mathrm{R}^{\prime}\left(\mathrm{r}_{\mathrm{x}}^{\prime}, \mathrm{r}_{\mathrm{y}}^{\prime}\right)$ \\
\hline $\begin{array}{c}\text { Correspondingimage points on } \\
\text { thescreen }\end{array}$ & Cinema: $\mathrm{I}_{\mathrm{L}}\left(\mathrm{i}_{\mathrm{L}}^{\mathrm{x}}, \mathrm{i}_{\mathrm{L}}^{\mathrm{y}}\right), \mathrm{I}_{\mathrm{L}}\left(\mathrm{i}_{\mathrm{R}}^{\mathrm{x}}, \mathrm{i}_{\mathrm{R}}^{\mathrm{y}}\right) / 3 \mathrm{DTV}: \mathrm{I}_{\mathrm{L}}^{\prime}\left(\mathrm{i}_{\mathrm{L}}^{\prime \mathrm{x}}, \mathrm{i}_{\mathrm{L}}^{\mathrm{y}}\right), \mathrm{I}_{\mathrm{R}}^{\prime}\left(\mathrm{i}_{\mathrm{R}}^{\mathrm{x}}, \mathrm{i}_{\mathrm{R}}^{\prime \mathrm{y}}\right)$ \\
\hline Screen & Cinema:d / 3DTV: $\mathrm{d}^{\prime}$ \\
\hline Viewing & Cinema: $\mathrm{t} / 3 \mathrm{DTV}: \mathrm{t}^{\prime}$ \\
\hline
\end{tabular}

\section{Perception Correctionin 3DTV}

First, we discuss the relative depth correction technique. The goal of this correction is to adapt the disparity of the 3DTV image pair, such that the apparent depths scale consistently and proportionally to the reduction in screen size. This implies:

$$
\overline{r_{y}} / r_{y}=t^{\prime} / t
$$


where, $\overline{\mathrm{r}_{\mathrm{y}}}$ refers to the $\mathrm{y}$-coordinate of the new object point.If $\overline{\mathrm{d}}$ is the adapted disparity value for consistent depthscaling:

$$
\overline{\mathrm{r}_{\mathrm{y}}}=\mathrm{e} * \mathrm{t}^{\prime} /(\mathrm{e}-\overline{\mathrm{d}})
$$

Dividing (2) by $\mathrm{r}_{\mathrm{y}}=\mathrm{e} * \mathrm{t} /(\mathrm{e}-\mathrm{d})$ gives $\overline{\mathrm{y}} / \mathrm{r}_{\mathrm{y}}=\mathrm{t}^{\prime} / \mathrm{t}[\mathrm{e}-\mathrm{d} / \mathrm{e}-\overline{\mathrm{d}}]$. Thus for the condition in (1) to be satisfied, we must have $\bar{d}=d$, whichmeans that the disparity values of 3DTV content should besame as those of 3D cinema. As a result, a correction valuegiven below should be applied to the no-transform 3DTVcontent for the relative depth correction.

$$
\text { correction }=\mathrm{d}-\mathrm{f} * \mathrm{~d}=\mathrm{d} 1-\mathrm{f}
$$

This means that the correction to be applied on the content varies across the image depending on the disparity of the cinema content. Thus, no single correction value can be applied over the image(s). As a result, relative depth correction requires complex solutions involving computationally intensive depth map calculations [10].

\section{Subjective Tests}

Results of the subjective tests, for each video, are presented in 2 graphs. The first graph shows results for the depth quality attribute, for both free (FW) and directed viewing (DW) tests. The $\mathrm{X}$-axis refers to the transformation and corresponding pixel shift. The $\mathrm{Y}$-axis refers to the meanopinion-score (MOS) for depth quality (S-Excellent, 4-Good, 3-Fair, 2-Poor, I-Bad). The second graph shows results for the visual comfort attribute, for both FW and DW tests. The X-axis refers to the transformation and corresponding pixel shift. The $\mathrm{Y}$-axis refers to the MOS for visual comfort (S- No discomfort experienced, 4-Disconfort experienced but not annoying, 3-Slightly annoying, 2-Annoying, I-Very annoying). The results of the subjective tests for the different video sequences considered. The notations given below are used to refer to the disparity-based transformations considered in the study.

Separate free viewing and directed viewing sessionswere conducted in all tests to investigate the differences inresponse of the viewers. Results show that both free anddirected viewing give similar subjective ratings for bothattributes considered.

\section{Conclusions}

The success of 3DTV will be in giving every viewer a satisfactory 3D experience with an acceptable level of visual comfort, irrespectively of the display size being used. In this paper, we explore the effect of using directly on 3DTV the content originally meant for 3D-cinema. We show that this approach has a considerable impact on the apparent depth. Although it would be possible, it is clearly not viable to produce multiple streams of the same 3D content for cinema and TV screens. Thus, we show that by using a simple shift based disparity transformation technique, it is possible to enhance the 3DTV experience from a common input signal, which was originally captured for cinema viewing. In general, transformations A3 and A2 can be used to improve the depth quality of 3DTV experience. However, we recommend A3 as it preserves visual comfort of 3DTV viewing. Clearly, further studies are needed for the acceptability of these solutions. In future, we plan to firmly understand the overall acceptance of each transformation by conducting further tests in the 3DTV environment, and comparing the experience to that of cinema environment. 


\section{Acknowledgement}

This work was supported by the Liaoning Provincial Education Department (W2013280); Scientific Research Foundation for the Returned Overseas Chinese Scholars, State Education Ministry; Research Fund for the Doctoral Program of Dalian University.

\section{References}

[1] F. Devernay and S. Duchene, "New view synthesis for stereo cinema by hybrid disparity remapping," International Conference on Image Processing (ICIP), September. 2010.

[2] B. Michel, "Production issues with 3D content targeting cinema, TV, and mobile devices", European digital cinema forum. Available at: http://www.edcf.net/3d.html

[3] D. Di Sorte, M. Femminella, A. Parisi, and G. Reali,"Network delivery of live events in a Digital Cinemascenario," in Optical Network Design and Modeling, 2008.ONDM 2008. International Conference on, 2008, pp. 1-6.

[4] D. Di Sorte, M. Femminella, A. Grasselli, and G. Reali,"Network Distribution of Digital Cinema Contents," in Mobileand Wireless Communications Summit, 2007. 16th IST, 2007,pp. 1-5.

[5] D. Scharstein and R. Szeliski, A Taxonomy and Evaluation of dense Two-Frame Stereo Correspondence Algorithms, International journal of Computer Vision, April 2002, Vol.

27, No. 1-3, pp 7-42.

[6] D. Seigle and J. Sanders, "3D's Immersive Experience at Home: Why the home 3D experience will Not Rival that of the Theatre" In-Three, Available athttp://www.practicalhome- theater-guide. com/support-files/3dinthehome-v2.pdf

[7] J. A. Bloom, "Digital Cinema Content Security and the DCI,"in 2006 40th Annual Conference on Information Sciences andSystems, 2006, pp. 1176-1181.

[8] L. Chauvier, K. Murray, S. Parnall, R. Taylor, and J. Walker, "Does size matter? The impact of screen size on stereoscopic 3DTV," presented at the IBC Conference, Amsterdam, Netherlands, September 2010.

[9] M. D. Smith and J. Villasenor, "Constant quality JPEG2000rate control for digital cinema," in Proc. SPIE InternationalConference on Visual Communications and ImageProcessing, 2007.

[10] W. Chen, J. Fournier, M. Barkowsky and P.K. Callet, "New requirements of subjective video quality assessment methodologies for 3DTV", Video Processing and quality Metrices (VPQM), version 1, 12 March 2010. 